\title{
Chain Versus Belt - System Comparison of Future Timing Drives
}

\author{
Michael Howlett ${ }^{1)}$ Norbert Ausserhofer ${ }^{2)}$ Wolfgang Schoeffmann ${ }^{3)}$ Caroline Truffinet ${ }^{4)}$ Andreas Zurk ${ }^{5)}$ \\ 1)-5) AVL List Gmbh, Hans List Platz 1, 8020 Graz, Austria
}

Received on August 7, 2015

Presented at the JSAE Annual Congress on May 20, 2015

\begin{abstract}
The challenge for the development of future gasoline and diesel engine families is further increase of efficiency at increasing cost .pressure. Downsizing as a main engine trend for significant $\mathrm{CO}_{2}$ reduction with increased loads on the engine systems as well as engine lifetime requirements have a considerable impact on the layout and the quality requirements of timing drives. In the paper the main timing drive concepts, chain drive, dry belt and wet belt were analyzed and rated based on the functional influencing factors as target parameters to allow a scientifically based guidance for finding the most suitable timing drive concept.
\end{abstract}

KEY WORDS: heat engine, timing drive, vibration/ noise [A1]

\section{Introduction}

When designing a new internal combustion engine, the choice of technology for the timing drive system is one of the key decisions that determines the overall characteristics of the engine with far reaching implications on the remaining architecture and overall packaging of the engine. For Passenger car engines there are two mainstream technologies: toothed belts and chains. Each of these offers several sub-variants, such as dry vs. wet belt, or toothed vs. roller chain.

This paper examines the differences between these technologies in relation to the key engine attributes including package, weight, durability, $\mathrm{NVH}$ and friction. A quantitative evaluation is made where possible, based on data collected from recent engine development programs, backed up by literature study and data from the component supply industry.

These differences are reviewed based on current and expected future engine development trends in order to give a basis for the engine designer to choose the best technology for a new engine design.

\section{Current status of timing drive system}

The primary function of the timing drive system is to drive the engine's camshafts with a fixed speed ratio of 1:2 and a constant timing relationship to the crankshaft. Several technologies can fulfill this function, such as gear, chain or belt drives. The selection of the appropriate system for a particular application must be made based on an evaluation of the performance in relation to the key attributes at engine system level, typically:

- Frictional losses

- Durability and Maintenance

- Timing Accuracy over lifetime

- Dynamic Behavior

- $\quad \mathrm{NVH}$

- Weight

- Packaging

\section{- Production Cost}

Gear drives are common for very highly loaded applications, such as heavy duty diesel engines, where the higher cost and noise levels of gear drives are balanced by long durability and capacity for high torques. Toothed belts and chains are established as the primary solutions for passenger car engines worldwide.

\section{Engine technology trends}

Fuel consumption and $\mathrm{CO}_{2}$ emission legislation is the main driver for future engine development worldwide ${ }^{(1,2)}$.

Downsizing of the engine to improve vehicle fuel consumption increases specific power and thus cylinder pressures and oil temperatures. Downsizing through reduced number of cylinders causes higher crankshaft dynamics and higher cam torque excitation due to the lower firing frequency. The use of small turbocharged engines in relatively heavy cars increases the average load profile and hence the mechanical and thermal loads on the engine components.

Real Driving Emissions (RDE) measurement will be introduced in Europe, extending the engine operating range where emissions and fuel consumption are regulated. For gasoline engines, stoichiometric operation with active 3-way catalyst will extend up to full load, while for diesel engines NOx aftertreatment will become standard. Soot emissions will increase with the continued trend to direct injection and external cooled EGR for both diesel and, increasingly, gasoline engines.

Compatibility with worldwide fuels requires high material resistance to chemical influence causing corrosion. Meanwhile, stress on the engine lubricant will increase due to the combination of high power density, reduced oil capacity and flexible oil change intervals. Low viscosity oil will be increasingly common and will influence the wear behavior of the timing drive.

The technology roadmaps (Figures 1 and 2) summarize the main development directions for gasoline and diesel engines. The technologies are color coded according to their influence on the timing drive layout of current and future engines. 


\subsection{Influences on timing drive - Gasoline Engines}

The continued trend to turbocharging and downsizing leads to increased cylinder peak pressures, reaching up to $13 \mathrm{MPa}$, nearly double that of typical NA-MPI engines.

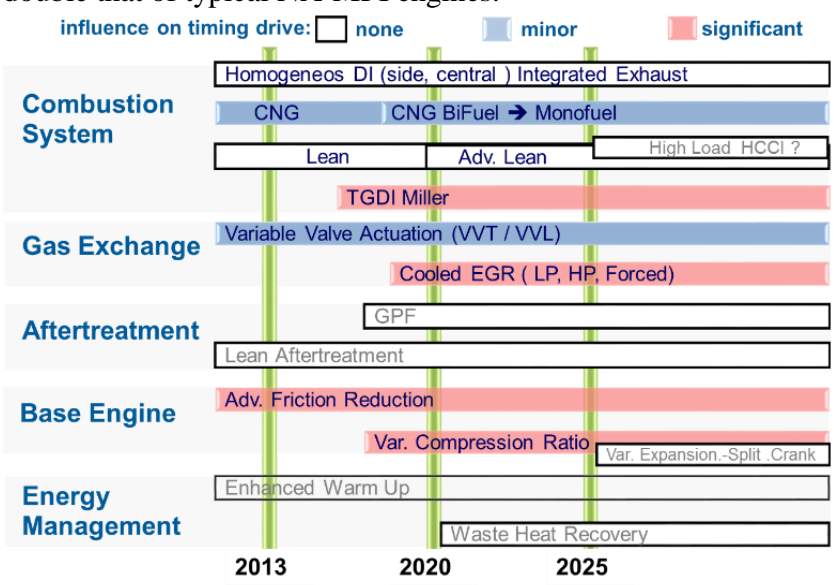

Fig. 1 Technology road map - Gasoline engine

Friction-optimized crankshafts have reduced bearing diameters and hence lower torsional stiffness. Consequently, the crank train dynamic input to the timing drive increases. Increasing GDI Injection pressures in the range currently of 20 to $25 \mathrm{MPa}$ result in higher camshaft torque peaks from the fuel pump drive. New designs are already being protected for future increase up to double these values. Furthermore, GDI combustion causes soot contamination of the oil as already known at diesel engines, though at lower levels.

Aggressive fuel economy concepts will be introduced such as Miller cycle with high compression ratio. This approach demands reduced combustion chamber volume.and wider cam timing variation. The valve to piston clearance and hence the timing accuracy becomes the limiting factor for the combustion chamber design. Cooled EGR allows extension of stoichiometric operation towards full load for improved real world fuel consumption, but will lead to an increase in oil contamination.

Dual-VVT will become mainstream, due to the benefits in lowend torque and fuel consumption for TC engines. Dual-VVT typically increases timing drive dynamics.

\subsection{Influences on timing drive - Diesel Engines}

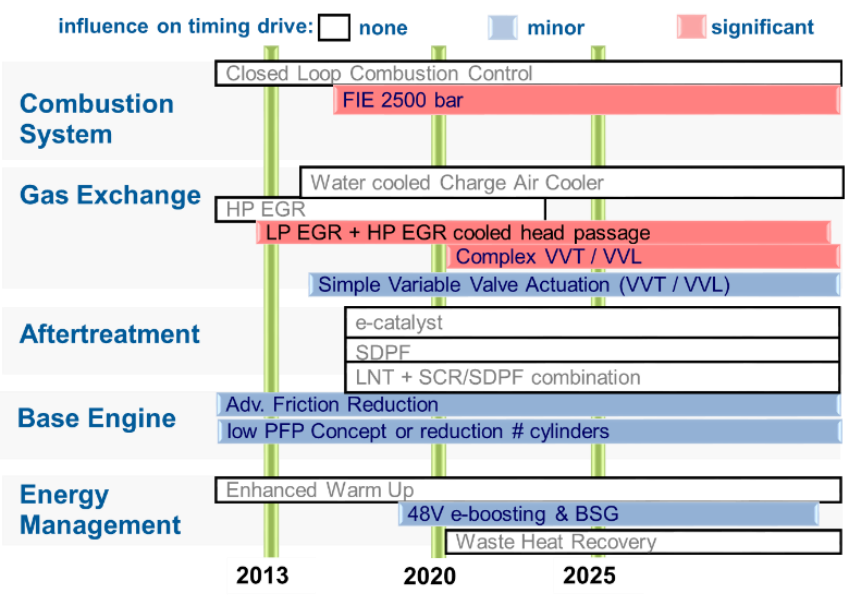

Fig. 2 Technology road map - Diesel engine
Peak cylinder pressures remain at today's levels, up to $20 \mathrm{MPa}$ for high performance engines, and at the opposite extreme down to $13 \mathrm{MPa}$ for aggressive fuel economy concepts.

Increasing injection pressure of up to $300 \mathrm{MPa}$ will cause an increase of the high pressure fuel pump drive torque peaks. The introduction of VVT and/or VVL for after-treatment thermal management at selected applications, currently not seen as mainstream before 2025 , will affect timing drive dynamics. The higher cost of sealed VVT units for dry belt drives will become relevant for Diesel engines.

Meeting RDE (Real Driving Emissions) will require higher EGR rates as well as higher performance of the after-treatment system. The resulting increase of soot in oil will be more severe for the mechanical wear of the timing drive.

\section{EVALUATION OF TIMING DRIVE CONCEPTS}

\subsection{Friction}

The contribution of the timing drive system is typically less than $5 \%$ of engine friction. Nevertheless the current focus on $\mathrm{CO}_{2}$ reduction makes it necessary to consider every small contribution at the concept stage of a new engine design, and to seek ways to minimize the overall losses.

The traditional picture in timing drive friction measurements shows a clear separation of the friction levels of belt driven and chain driven systems ${ }^{(3)}$. However, recent strip down measurements performed on state of the art engines show no systematic differences between belt drives and chain drives in terms of timing drive friction. The lower end of scatter band for gasoline engines is on a very similar level for chain- and belt drive systems.

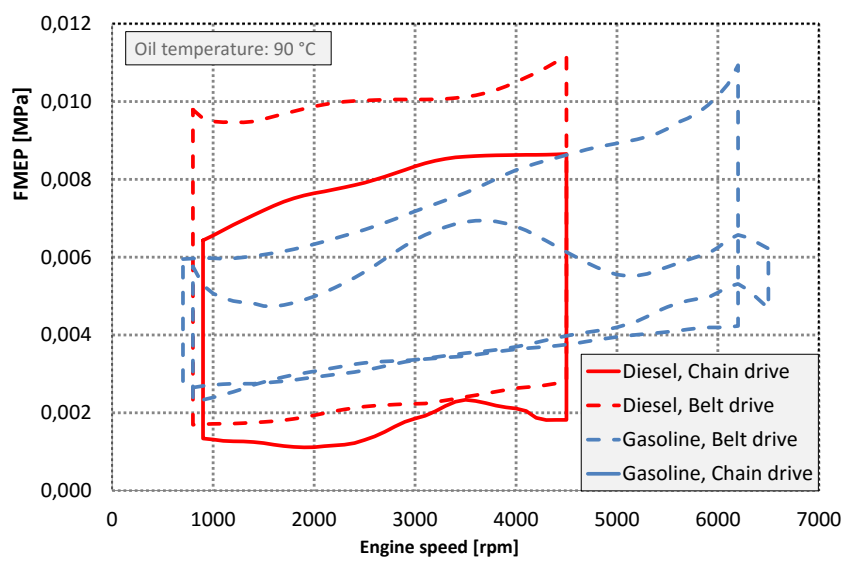

Fig. 3 Measured friction of the timing drive and camshafts

Figure 3 summarizes the measured timing drive friction results for 12 gasoline and 8 diesel passenger car engines from stripdown testing. The results show a rather wide range of friction values with significant overlap of the scatter bands for different categories. The best chain drives are better than the average of the belt drives, and vice versa. The lower end of scatter band for gasoline engines is on a very similar level for chain- and belt drive systems.

From this, we conclude that the influence of the overall drive layout is a more significant factor than just the choice of belt or chain. Comparing timing drive layouts shows that a simple arrangement with direct crank to cam connection - without 
additional components requiring large wrap angles - leads to the lowest possible FMEP values for timing drives. Direct chain drives with just two sprockets have very similar friction levels to simple belt arrangements.

Inverted tooth chains have a higher friction than bush and roller chains, based on AVL measurements. Development efforts including new chain development with optimized link contact, tooth geometry and coating technologies show the potential for further detailed optimization to reduce friction.

Belt drive suppliers are also working on development of new compounds and coatings to reduce friction.

\subsection{Durability}

The typical durability requirements for a passenger car engine are between 200 and 250 thousand $\mathrm{km}$ and 15 years product lifetime without major failure. Both chain and belt systems are implemented in such engines. System lifetime and the need for adjustment or replacement of timing drive components within the engine life are often an important consideration for the timing drive concept decision.

\subsubsection{Main Failure Modes}

The main failure mode of chain drives is the elongation over lifetime due to abrasive wear at the joints between pins and plates. The rate of chain elongation depends on the oil deterioration and soot content. A chain elongation of $0.3 \%$ to $0.6 \%$ is typically considered as layout criterion, based on the selected chain type and the expected oil deterioration. Because wear accumulates gradually over time, the detection of this failure mode is relatively simple by measurement of the increasing cam timing error using sensors already available for engine control.

The main failure mode of belt drives is tooth shear.The tooth shear starts with cracks in the root area of the teeth followed by partial and finally complete shear of teeth. These effects lead eventually to total timing drive failure and consequently severe engine failure. The detection of tooth shear initiation is hardly possible, defects only becoming apparent when they are already quite large. Visual inspection is sufficient to detect larger defects and is therefore specified by some OEMs as part of regular service. Since the onset of tooth shear does not cause a timing error, detection by sensors is currently not available.

\subsubsection{Valve timing over engine life time}

Changes in the length of the belt or chain over time lead to a timing error, the valve timing becoming gradually later. As well as effects on the engine thermodynamic cycle, this also brings the exhaust valves closer to the piston. Figure 4 illustrates the effect on valve timing and piston to valve clearance of $0.4 \%$ and $0.6 \%$ elongation compared to nominal length.

The exact effect of a timing error varies according to the combustion system but the timing drift of $8^{\circ}$ crank angle over lifetime is generally considered acceptable for current requirements including emissions durability of 160 thousand $\mathrm{km}$. Future increase of emission durability requirements would require a re-evaluation of this limit. In particular The $0.3 \mathrm{~mm}$ difference in valve lift becomes significant when designing new combustion systems with high compression ratio and extreme cam phasing ranges, for example for Miller Cycle ${ }^{(4)}$.

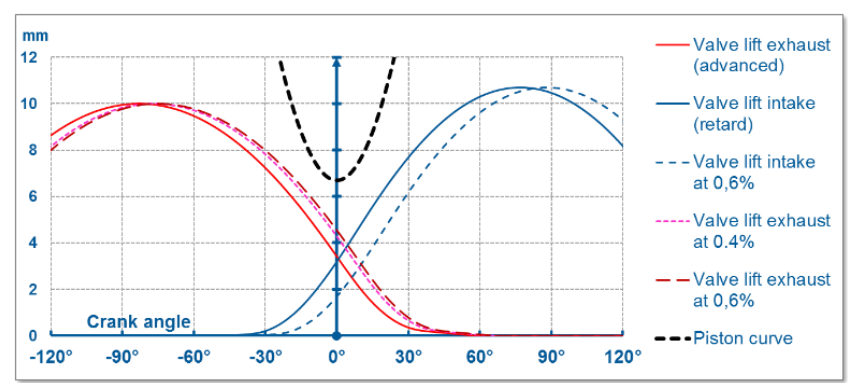

Fig. 4 Effect of Elongation on valve timing and clearance

Belts do not elongate due to wear, but there is some permanent elongation due to setting of the cords under tension. Measurements of the wet belt on a I3-Cylinder-T-GDI production engine showed $0.14 \%$ permanent stretch under a static load of 500 $\mathrm{N}$. This elongation can be compensated during the belt assembly process where the full static pre-tension is applied by the mechanical tensioner before fixing engine timing. In chains, this kind of initial elongation is eliminated by pre-stressing the chains during the manufacturing process, which is currently not standard for belts.

The belt elongation over lifetime varies depending on the belt technology used with different belt suppliers specifying values between $0.1 \%$ and $0.25 \%$ as layout criteria. The development trend is towards the lower end of this range.

Chain systems have a potential disadvantage compared to belt drives in regard to consistency of valve timing over engine life time.

\subsubsection{Environmental Robustness}

Timing drive durability is sensitive to environmental factors: engines which operate without problems in one market may experience repeated failures in another market due to different customer duty cycles, fuels and lubricant specifications.

Dry belts are exposed to ambient influences such as temperature, dust and humidity. These can reduce the belt lifetime. The "dry" belt is not completely sealed and may be exposed to water splash, snow and debris from the road surface. The temperature profile over lifetime varies according to duty cycle and environment.

Enclosing the belt in the engine oil provides more consistent temperature and humidity conditions as well as excluding debris. Instead, belt materials are now exposed to engine oil containing soot as well as chemicals such as unburned fuel, and acidic components from EGR gases. Of the chemicals tested, ethanol fuel, glycol/water coolant and blow-by condensate are those with highest influence on belt swelling, belt tension reduction and tooth adhesion reduction in different static tests. Particularly critical pure chemicals are: Acetic acid, Glycol and Ethylhexanoic acid depending on concentration and belt type. Though the belt itself is not sensitive to soot in oil, other components of the drive such as idler bearings or tensioner are potential critical areas.

The critical influencing factor on chain wear is soot as well as fuel in oil. The inverted tooth chain is more sensitive to oil deterioration than bushed chain, due to the smaller diameter of the chain pins. High performance TGDI applications with increased oil deterioration and chain dynamics are becoming critical for IT chain application.

Robustness against abrasive wear is a key focus for chain development and is addressed by changes in the chain design to increase bearing area as well as improvements in production precision, material and heat treatment.

\subsubsection{Maintenance}


Chain drives are generally considered a lifetime system. Consequently, there usually is no requirement for visual check or chain replacement in service. Maintenance due to on-board detection of timing error is already introduced by some OEMs.

Design lifetime of dry belt drives has increased due to improved belt technology from a norm of 10 up to 15 years. However, some OEMs still specify planned belt replacement intervals within the design life. Reduced replacement intervals may be specified for severe markets (e.g. high ambient temperature and dusty environments). Some OEMs specify that visual checks of the belt are needed due to aging and ambient influences.

Belt in oil drives are designed, like chains, for engine lifetime without maintenance. They have a long history in industrial engine applications but for automotive applications, they are a relatively new technology. The field experience in volume production is limited currently to one diesel and two gasoline applications but so far, no critical field issues are observed. Visual checks for wet belt drives (if required by the OEM) would result in high service effort, e.g. the disassembly of the oil sealed cover or additional service openings for visual check.

\subsection{Dynamic Behavior}

The timing drive system transmits torque from the crankshaft to the camshafts. The engine crankshaft speed varies over the cycle due to the impulses of the different pistons. Also the camshaft drive torque varies over the cycle due to the cam profiles, and may reverse due to the reaction torque from the valve springs. The relative phases of these loads may be varied by VVT devices and all of these influences change with engine load and speed. The whole system is thus a highly dynamic one and the layout of the geometry and the tensioning system has to be designed to cope with this. Evaluation criteria are the maximum belt or chain tension which must remain below the design limit for the chosen technology (while avoiding zero force conditions representing loss of control) and the dynamic timing error due to relative torsional vibration at the camshaft.

Typically, mechanical or hydraulic tensioner systems have comparable performance characteristics. Mechanical systems typically used on dry belts have the advantage of being independent from engine oil condition and oil pressure.

Typical timing drive systems have at least one resonance in the engine speed range as shown in Figure 5.

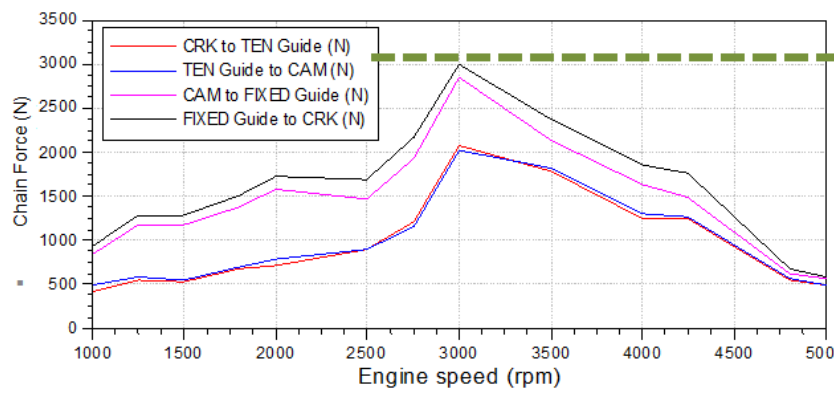

Fig. 5 Chain timing drive - dynamic forces

Due to their lower stiffness, belt drive systems frequently exhibit two separate resonance areas appearing within the engine operating speed range as shown in Figure 6. However, this is of itself not an issue if the force peaks are within the design limits.

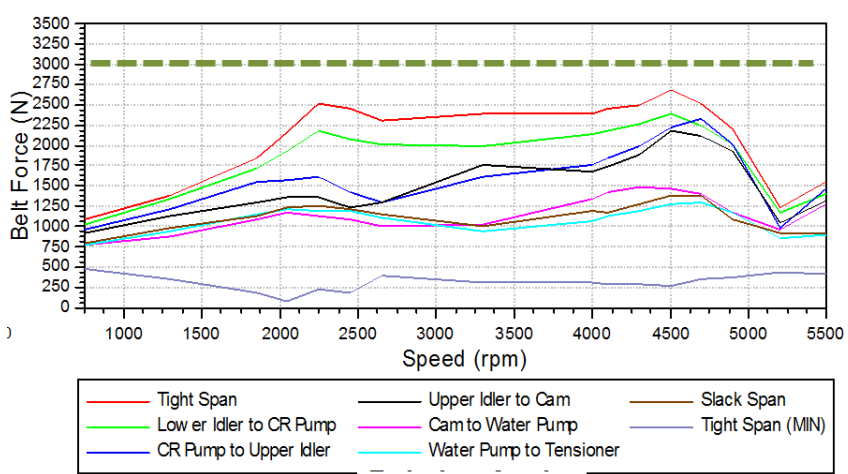

Fig. 6 Belt timing drive - dynamic forces

The fuel injection pump torque is one of the main loads to the timing drive. Future gasoline fuel injection pump driving torques are expected to further increase to reach the level of today's diesel injection pumps, while diesel injection pressures and torques also increase further. Very high torque peaks are directly converted to high tensions in a stiff chain, whereas a belt can reduce force peaks through its flexibility.

Reference examples of chain drives as well as belt drive systems show values in a similar range. The timing error is not constant over the entire engine cycle; a maximum dynamic deviation of 3 to $4^{\circ}$ crank angle is considered normal and does not lead to an emission or performance penalty.

\subsection{NVH Behavior}

Timing drive related noise phenomena can be classified into two categories: inherent noises and avoidable noises. The meshing noise is the major noise phenomenon, and is inherent to the meshing process of the belt or chain with the sprocket. This process creates whine noise with a discrete frequency (and its multiples) which is related to the speed and the number of teeth of the sprocket. As an example, Figure 7 illustrates the meshing noise created by a crankshaft sprocket with 21 teeth.

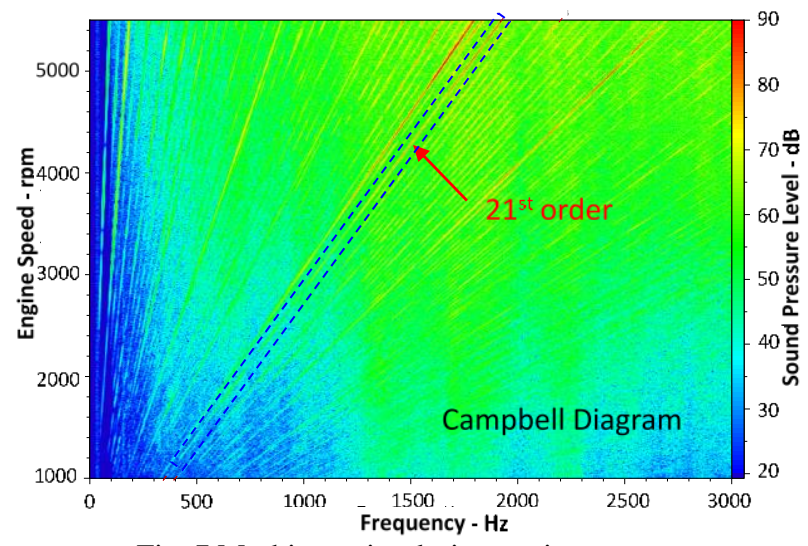

Fig. 7 Meshing noise during engine run-up

The meshing noise can be reduced by concept choice and detail design work, but cannot be eliminated as it is inherent to the meshing process. For all drives, fine tuning of the tensioner/belt or tensioner/chain system helps to reduce the meshing noise. For belt drives, lowering belt tension reduces the meshing noise. For chain drives, small pitch, choice of the chain type, sprocket teeth geometry and special features (such as rubber coated sprockets or cushion rings) are efficient measures for lowering the meshing noise. 
The other category of noises can be avoided or strongly reduced by applying design rules. The major conception and design rules are:

- For belt drives:

o Transverse belt span vibrations due to long belt spans can be avoided by the use of additional idler pulleys.

o The belt excitation due to production surface irregularities of belt, rollers and idlers can be avoided by setting tight production tolerances.

o The abnormal noise caused by misalignment of the timing drive components can be avoided by setting tight design tolerances.

o Increased roller bearing noise due to dust penetration can be avoided by improving the belt cover sealing or by using dust protected bearings.

o Noise amplification by the cover can be avoided if the cover is optimized:

- With a dry belt, the cover should be decoupled (stiff and thick plastic cover) and the stiff mount bracket should be fixed at engine block front side.

- With a wet belt, a stiff metal cover with integrated mount bracket should be used.

- For chain drives:

o Transverse chain span vibrations due to long chain spans can be avoided by the use of guiding rails.

o The knocking noise coming from the interaction between the chain and the guides can be avoided by optimizing the shape of the guiding rails, particularly at the rail ends.

o The noise amplification by the cover can be avoided by using a stiff metal front cover with integrated mount bracket.

o The risk of hydraulic tensioner knocking noise at cold start or stop-start re-starts (until oil pressure is fully builtup) can be eliminated if enough volume of the oil reservoir is available, so that the oil pressure drop is minimized.

The following results and conclusions are based on the analyses of NVH test results of 13 well developed engines measured in acoustic test cells. The assessments have been performed both on the airborne noise and on the vibration measurements. The clearest conclusions could be obtained with the airborne noise measurements, for which the following criteria were applied:

- Comparison of overall level at engine front and top microphones.

- Comparison of meshing order level at engine front and top microphones.

- Comparison of the meshing noise audibility, based on the commonly used " $-10 \mathrm{~dB}$ threshold". The meshing order level is compared to the overall level minus $10 \mathrm{~dB}$ : if the order level is higher than this limit, there is a risk of audible meshing noise. This is illustrated in Figure 8.
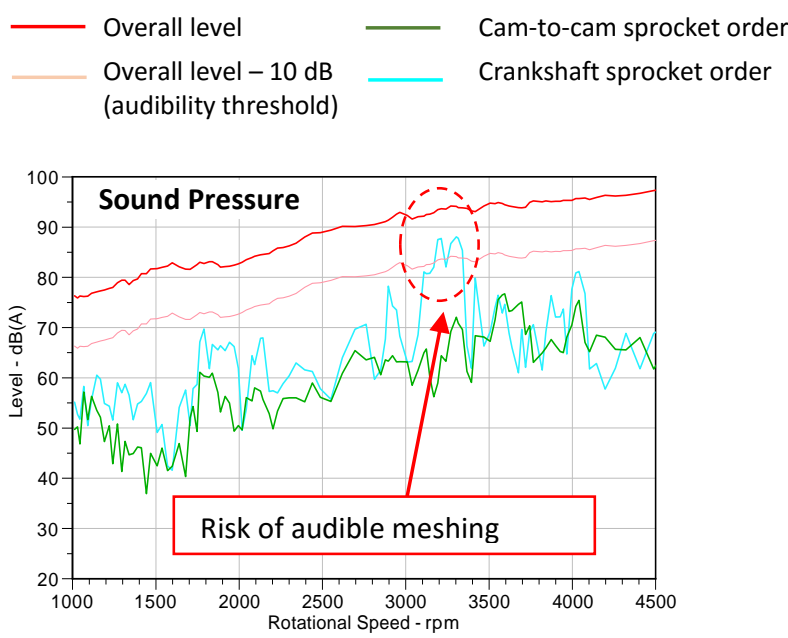

Fig. 8 Risk evaluation for audibility of meshing noise

Generally, the risk of audible meshing noise is low with welldeveloped timing drive systems, for both chain and belt drives. However, due to less masking effects from the engine noise, this risk is higher at low load conditions than at full load.

If meshing noise becomes audible, chain noise is usually more annoying than belt noise because of the sharper noise character which is associated with the metal-to-metal contact between chain and sprocket.

Regarding overall engine noise, Figure 9 shows the situation for the noise levels measured on gasoline engines in an acoustic engine test cell at $1 \mathrm{~m}$ in front of the timing drive cover, under no load conditions.

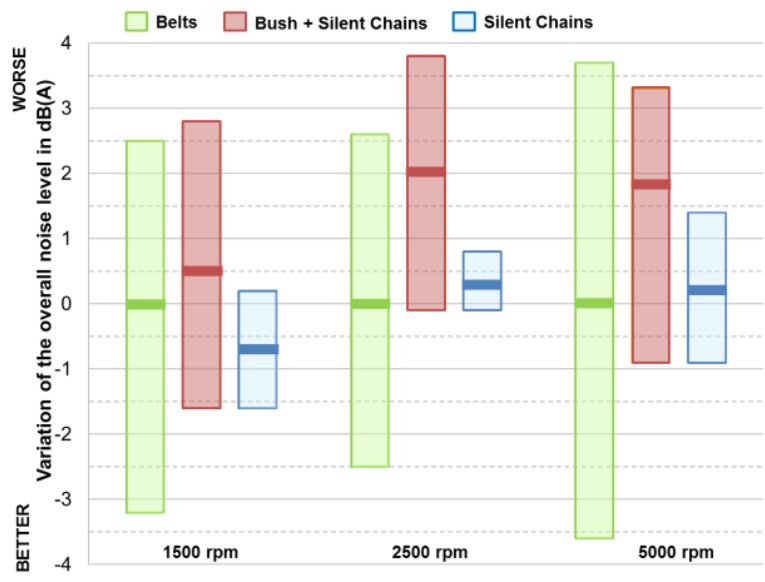

Fig. 9 Noise of gasoline engines at engine front side

The thick line in Figure 9 represents the average (mean) level, the box represents the scattering between best and worst engines. The average levels are represented with respect to the belt drives average (green average $=0 \mathrm{~dB}$ ).

When overall noise level is considered as shown in Figure 9, the mean level of silent chain drives is lower than with bush chain drives and is very similar to that of belt drives, sometimes even lower.

However, the variation of the overall noise level within one type of timing drive is much higher than the typical mean differences between chain and belt drives. Indeed, the strong influence of the engine structural dynamics on the radiation of the timing drive induced noise contributes significantly to this big 
variation. This effect may be further enhanced by the dynamic behavior of the engine installation in the vehicle and the dynamics of the vehicle body. But in the end, both chain and belt drives can enable good vehicle acoustics, if the timing drive system and the overall engine and vehicle $\mathrm{NVH}$ are well developed.

In summary, it can be concluded that

- belt drives generally have very good NVH behavior (as the timing drive cover is not fully sealed, ambient influences, such as contamination by dust, can deteriorate the $\mathrm{NVH}$ behavior).

- wet belts show superior overall NVH because of the stiff structure of the oil sealed cover combined with the good NVH behavior of the belt.

- all chain drive concepts can reach good engine NVH characteristics if the major engine conception rules are considered.

- non-optimized chain drive layouts with noticeable whine noise may result in a sharp and annoying noise character.

- $\quad$ inverted tooth chains, also called silent chains, achieve comparable NVH performance to belt drives.

\subsection{System weight and packaging}

The timing drive components themselves (chain or belt, sprockets and idlers/guides/tensioners) amount to around 2-3\% of the engine weight but the related components such as VVT as well as the covers for the drive have to be considerd to give an overall influence on engine weight.

Figure 10 shows a weight analysis of 3 production engines, with camshaft driven GDI fuel pump and dual VVT.

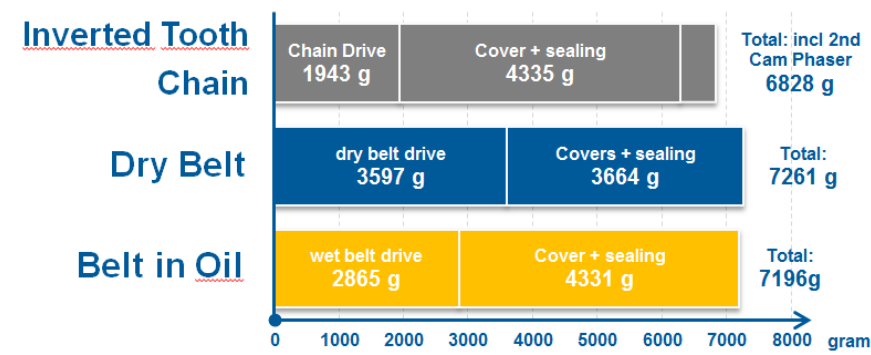

Fig. 10 Gasoline engine timing drive weight comparison

In this example, the chain system exhibits the lowest total system weight by a small margin. The belt drive suffers from the penalty of additional sealing for a dry belt VVT unit of about 400 $\mathrm{g}$ per camshaft. In addition, the belt sprockets and tensioners are heavier than those for chain drives. Finally, the dry belt needs a separate front engine mount bracket (to give access for belt maintenance) whereas for the wet belt and chain designs, the bracket is integrated in the structural aluminium cover.

For engine packaging the engine length and height are most critical. Minimum engine height is a required for pedestrian protection in combination with low vehicle hood lines. In transverse installations (where engine and gearbox must fit inside the vehicle frame members) the engine length is restricted. The timing drive directly influences both dimensions.

Belt drives for gasoline engines typically require larger pitch than chains and result in larger sprocket diameters at the camshaft. The camshaft sprockets (with appropriate covers) are often the highest part of the engine so a reduction of this diameter has a direct benefit in engine height.

After the cylinder spacing, the required space for the timing and oil pump drive, typically packaged immediately in front of the first cylinder, is the next decisive factor for the overall engine length. The shortest engine is the one with single chain drive to the camshaft, additional length comes from the belt width itself, which is a variable dependent on loading and lifetime requirements. For gasoline engines the length benefit of a chain is in the range of 9 to $15 \mathrm{~mm}$ currently. A reduction of the required belt width for a given load has been achieved in the past with belt technology development and further improvement potential is under active investigation. However even with these expected reductions the belt system is likely to remain wider than the bushed chain solution, because the next generation of inverted tooth chains will be reduced in width. Changing the chain guide concept from outside- to inside-link contact, will save additional space.

\section{Timing drive system decision matrix}

The data discussed in the previous sections represents a synthesis of many different data sources and experience from involvement in a large number of engine development programs over the last decade. Based on this data, the authors have attempted to assign qualitative, relative ratings to the four main passenger car engine timing drive concepts: bush chain, inverted tooth chain, dry belt and wet belt. These ratings are summarized in Figure 11.

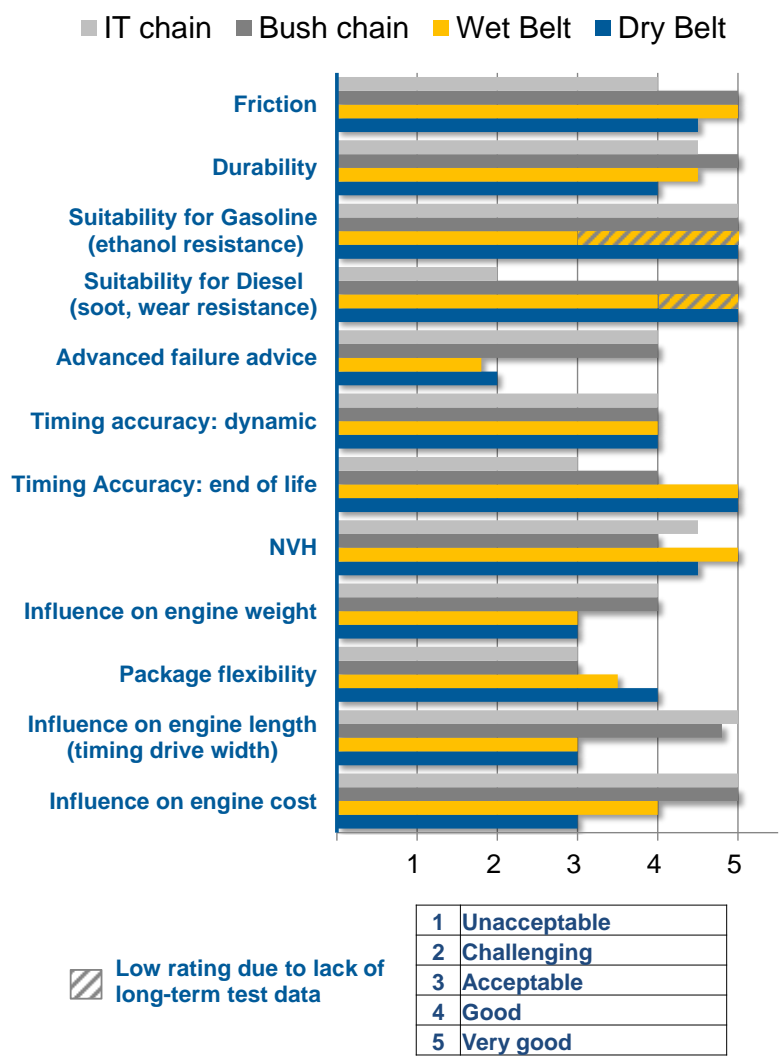

Fig. 11 Summary of ratings of four main drive technologies

Depending on the target engine application (OEM, market, vehicle type and weight, etc.), the various attributes will be weighted differently. The combination of the category ratings with the attribute weightings in a matrix offers a systematic approach to the concept decision between these different technologies.

\section{Conclusion}

The timing drive is one of the key engine systems and its layout is a significant part of any new engine layout. Various 
technologies are available which can be applied; for passenger cars the choice is usually made between chain and belt.

Future engine development will be focussed on $\mathrm{CO}_{2}$ reduction and extension of the emission relevant operating range within the engine map. These developments tend to increase the dynamic loading on the timing drive while also demanding more consistent accuracy of timing. At the same time global engine production increases the range of environmental influences on the timing drive components.

The performance of the competing drive systems is very similar and continual technological development at all suppliers means that the ratings must be subject to frequent critical revision. Based on the evidence presented, it is not possible to select a clear "best technology" that suits every engine application significantly better in all attributes.

The following key points summarize the current state of the art from the engine designer's point of view:

- Chain drives have an advantage over belt drives when absolute minimum engine length is required by vehicle package

- Where space allows, belt drives offer the option of adapting width to suit the loads which is more difficult with chain solutions

- Wet drives (chain or belt) are a lower cost solution for engines with hydraulic VVT, which in future will be a clear majority of gasoline engines and possibly some diesel engines

- Wet belt is a promising technology. Continued positive field experience with current applications is seen as a prerequisite for a breakthrough to a wider market acceptance

- Belt drives achieve higher timing accuracy at end of life. For future emissions and fuel consumption targets this is likely to increase in importance

- The loads from the fuel injection pump are crucial for the durability of belt or chain. Increasing injection pressures mean that many drives are close to the limits with current technology

- Irrespective of the chosen drive type, a careful layout respecting design rules and optimization loops are required in order to achieve the best results in $\mathrm{NVH}$, Friction, and dynamic behavior

- Layout and dynamic simulation are the foundation for a durable design but testing in all applicable environmental conditions is required

The intense competition between belt and chain concepts is expected to continue in future.

\section{References}

(1) European Parliament and Council, "Emission performance standards for new passenger cars as part of the Community's integrated approach to reduce $\mathrm{CO}_{2}$ emissions from light-duty vehicles", Regulation (EC) No 4143/2009, April 2009.

(2) U.S. Environmental Protection Agency, Office of

Transportation and Air Quality, "Model Year 2012-2016 Light-

Duty Vehicle Greenhouse Gas Emissions Standards and Corporate Average Fuel Economy Standards", EPA-420-F-10014, April 2010

(3) Krehl, D., Belt drive versus chain drive, MTZ, Vol. 74, No.12, p. 951-959 (2013)

(4) Kapus, P., Prevedel, K., Wolkerstorfer, J., Neubauer, M.

"200 g/kWh - Can The Stoichiometric Gasoline Engine Beat The Diesel?", Aachen, 22nd Aachen Colloquium Automobile and Engine Technology 2013 